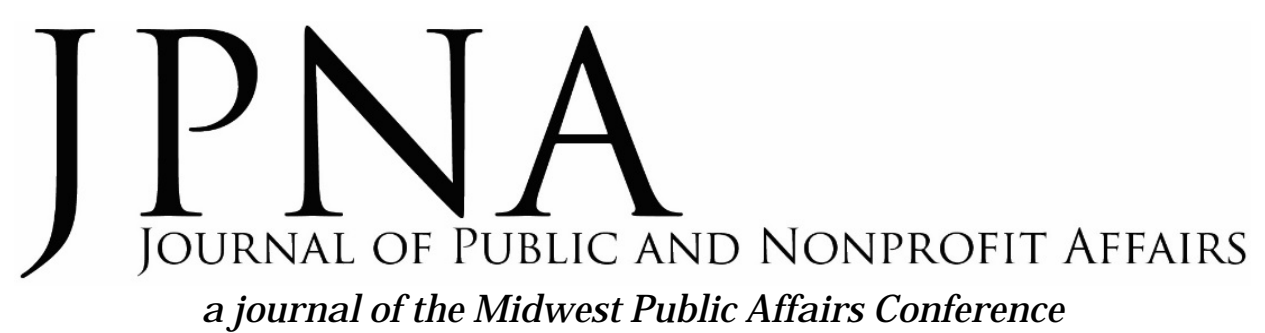

\title{
Spring 2016
}

\section{Volume 2, Number 1}

\section{Research Articles}

Sexual Minority and Employee Engagement: Implications for J ob Satisfaction Myung H.J in and J aehee Park ............................... 3

County Government Fleet Purchasing Practices: Financial Efficiency vs. Need Assertion Steve Modlin . . . . . . . . . . . . . . . . . . . . . . . . . . . . . . . . . . . 15

Acculturation and Informal and Formal Volunteering of Korean Americans in the United States Hee Soun J ang, Lili Wang, and Carlton F. Yoshioka ..................... 31

\section{Current Issues in Practice}

Veteran Family Reintegration: Strategic Insights to Inform Stakeholders' Efforts

Raun L. Lazier, Amy Warnick Gawne, and Nathan S. Williamson . . . . . . . . . . . 48

\section{Book Reviews}

Local Governance and Inter-Municipal Cooperation by Filipe Teles

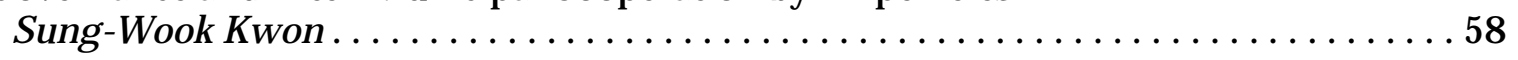


